\title{
The UK Network of Age-friendly Communities: a general review
}

DOI:

10.1108/WWOP-12-2017-0034

\section{Document Version}

Accepted author manuscript

Link to publication record in Manchester Research Explorer

\section{Citation for published version (APA):}

Rémillard-Boilard, S. (2018). The UK Network of Age-friendly Communities: a general review. Working with Older People, 22(1), 30-38. https://doi.org/10.1108/WWOP-12-2017-0034

\section{Published in:}

Working with Older People

\section{Citing this paper}

Please note that where the full-text provided on Manchester Research Explorer is the Author Accepted Manuscript or Proof version this may differ from the final Published version. If citing, it is advised that you check and use the publisher's definitive version.

\section{General rights}

Copyright and moral rights for the publications made accessible in the Research Explorer are retained by the authors and/or other copyright owners and it is a condition of accessing publications that users recognise and abide by the legal requirements associated with these rights.

\section{Takedown policy}

If you believe that this document breaches copyright please refer to the University of Manchester's Takedown Procedures [http://man.ac.uk/04Y6Bo] or contact uml.scholarlycommunications@manchester.ac.uk providing relevant details, so we can investigate your claim.

\section{OPEN ACCESS}




\title{
THE UK NETWORK OF AGE-FRIENDLY COMMUNITIES: A GENERAL REVIEW
}

\author{
Samuèle Rémillard-Boilard
}

\begin{abstract}
Purpose - This article aims to present a detailed account of the work and contribution of the UK Network of Age-friendly Communities, a platform established to support the development of age-friendly communities across the UK.

Design/methodology/approach - This article draws on a review of both external and internal working documents, communications with network representatives, and an in-depth interview conducted with the current manager of the UK Network of Age-friendly Communities.

Findings - Since its formation, the UK Network of Age-friendly Communities has provided cities with an important platform for knowledge exchange and peer support, and helped build commitment to the age-friendly agenda at the local, national and international level. Through the presentation of various examples, the article illustrates that network members have not only helped drive this agenda forward by developing a collective voice, but also by developing a wide range of initiatives at the local level.
\end{abstract}

Originality/value - Despite an increased interest in documenting age-friendly experiences around the world, the experience of national programmes remains underexplored in the agefriendly literature to date. To our knowledge, this article is one of the first to describe the work and contribution of the UK Network of Age-friendly Communities.

\section{INTRODUCTION}

The development of age-friendly policies has become a key strategy in response to the challenge of population ageing. Introduced by the World Health Organization [WHO] in 2005, the term 'age-friendly' characterises a city that 'foster[s] healthy and active ageing and, thus, enable[s] well-being throughout life' (WHO, 2015 p. 161). As part of an on-going process, age-friendly approaches aim to improve the environments in which people are ageing. According to the WHO (2015, p.161), age-friendly cities and communities should be good places to grow older: 'They [should] help people to remain independent for as long as possible, and provide care and protection when they are needed, respecting older people's autonomy and dignity'.

Starting with 33 participating cities in 2006, the age-friendly movement has grown significantly over the past eleven years. In 2017, 533 cities and communities had formalised their commitment to becoming more age-friendly by joining the WHO Global Network for 
Age-friendly Cities and Communities [GNAFCC], now an international network covering 158 million people worldwide (WHO, 2017a). Various factors have contributed to the growth of interest in the age-friendly approach, including the rapid ageing of the population, continued urbanisation, the promotion of active ageing, and the policy of 'ageing in place' (i.e. the emphasis on the desirability of older people to remain in their own homes for as long as possible). The endorsement of this movement by the United Nations, the WHO and the European Union also played a key role in driving the age-friendly agenda and encouraged the development of a wide range of age-friendly policies and initiatives at local, national, and international levels.

Despite an increased interest in documenting age-friendly experiences around the world (see, further, Buffel et al., 2018; Moulaert and Garon, 2016), the experience of national programmes remains under-explored in the age-friendly literature to date. This article aims to address this gap by giving a detailed account of the work and contribution of the UK Network of Age-friendly Communities, a national platform established to support the development of age-friendly communities across the UK. This theme is developed by: first, retracing the history and evolution of the network; second, reviewing the key principles of the age-friendly approach; and third, presenting four ways in which the UK Network can support the development of age-friendly communities. The article concludes by showcasing examples of projects undertaken by network members and discussing how the work and role of the network might evolve over time.

\section{HISTORY OF THE NETWORK}

The UK Network of Age-friendly Communities was developed as a result of an initiative by the UK Urban Ageing Consortium, a collaborative partnership bringing together the Manchester City Council, the University of Keele, and the Beth Johnson Foundation (2017), a UK national charity 'dedicated to making a future for all ages' [1]. The collaboration of these partners began in 2010, when the city of Manchester formalised its commitment to the WHO Global Network for Age-friendly Cities and Communities, becoming the first city in the UK to obtain age-friendly status. Building on the experience of Manchester's pioneering Valuing Older People programme (McGarry and Morris, 2011), the formation of the UK Urban Ageing Consortium aimed to advance practices and debates around urban ageing and 
further the development of age-friendly approaches across the UK (UK Urban Ageing Consortium, 2014).

The 2010-2012 period was a favourable time for the development of age-friendly initiatives in Europe, with the European Union declaring 2012 the European Year for Active Ageing and Solidarity between Generations, and AGE Platform Europe launching its campaign Towards an Age-friendly European Union by 2020. The growing interest in the development of agefriendly cities and communities in Europe and in the UK encouraged the UK Urban Ageing Consortium to develop a platform for cities to share their learning and experiences. A key milestone in the establishment of the network was the holding of a seminar entitled 'AgeFriendly Cities and Communities: Challenges and Opportunities' in 2011 (UK Urban Ageing Consortium, 2014). Convened by the consortium, the seminar aimed to bring together a wide range of cities and communities interested in becoming more age-friendly. This theme attracted interest from a variety of cities from across the UK, including Belfast, Leeds, Newcastle, Nottingham, Sheffield and Stoke-on-Trent, twelve of whom agreed to join forces and form what would become the UK Network of Age-friendly Communities.

Since the launch of the network, the twelve cities have been meeting regularly to exchange ideas and discuss the development of their respective age-friendly programmes. The Valuing Older People (now Age-Friendly Manchester) team played a key role in sustaining and developing the network over the years, absorbing the secretariat into their daily work and coordinating and promoting the network's activities. Ensuring the sustainability of this platform has, however, proven to be a challenging task given the broad scope and ambitions, but limited resources of the network. Members also faced challenges at the local level, with budget cuts often limiting the scope of their age-friendly work and leading to reorganisations and reductions in key staff (Entwistle, 2017).

The UK Network of Age-friendly Communities was re-launched in 2016 following the establishment of a strategic partnership with the UK Centre for Ageing Better [Ageing Better]. Funded by a $£ 50$ million ten-year endowment from the Big Lottery Fund, the Centre for Ageing Better (2017a) is an independent charitable foundation working to create a society in which everyone enjoys a good later life'. The Centre was established in 2015 in response to the publication of the House of Lords (2013) Select Committee on Public Service and Demographic Change report Ready for Ageing?, which argued that the UK government and society were 'woefully underprepared' to meet the needs of an ageing population. Part of 
the UK's What Works Network, Ageing Better aims 'to ensure that thorough, high quality, independently assessed evidence shapes decision-making at every level' (Cabinet Office, 2017). By testing new ideas and adopting an evidence-based approach to inform their work, the Centre aims 'to bridge gaps between research, evidence and practice' and bring about change so that people can age better in their community (Ageing Better, 2017b).

The Centre for Ageing Better has been especially interested in adopting a local approach to ageing issues and contributing to the development of age-friendly approaches and initiatives. The Centre is committed to supporting the UK Network of Age-friendly Communities and has allocated resources to hire a network manager for a two-year period to help further its development, and share and disseminate learning. Despite their close collaboration, the network remains an independent entity and is entirely driven by its members. The Centre aims to provide mechanisms and create infrastructures to support its development but participating cities are invited to set their own agenda and participate actively to its realisation.

The development of this partnership, along with the arrival of a new manager in January 2017, encouraged member cities to review their priorities. As a result, a new work plan has been established to redefine and clarify the aims of the network. The allocation of more resources also allowed the network to reach new communities and increase its membership. Over the period 2016-2017, the network increased its membership from 12 to 19, bringing together a range of communities from across the UK determined to increase their level of age-friendliness (Entwistle, 2017).

\section{DEVELOPING AGE-FRIENDLY INITIATIVES: THE WHO FRAMEWORK}

Increasing the age-friendliness of cities can be achieved in various ways. Whilst they share the same objective, age-friendly approaches aim to find local solutions to problems and issues which are context specific. As Warth (2016, p. 39) argues: 'just as there is no one-size-fits-all solution to meeting the needs of older people, there is no one-size-fits-all recipe for creating age-friendly environments'. Network members are invited to develop their own approach and mechanisms to become more age-friendly. The UK Network of Age-friendly Communities however encourages members to adopt the WHO age-friendly framework to structure and guide the development of their work. 
As the Centre for Ageing Better (2017c) has emphasised, the WHO framework is flexible and 'promotes a multi-sectoral approach to active and healthy ageing'. Following a large consultation conducted in 33 cities worldwide, the WHO (2007) identified eight areas cities could target to increase their level of age-friendliness: housing, transportation, outdoor spaces and buildings, community support and health services, communication and information, social participation, respect and social inclusion, and civic participation and employment. These eight domains are defined in greater detail in the WHO Global Age-Friendly Cities Guide (2007) and presented alongside a checklist which cities can use to help assess their level of age-friendliness.

In addition to encouraging cities to consider these eight domains, the WHO framework also recommends that older people be placed at the centre of age-friendly developments. A key principle underlying the development of age-friendly cities is that older people are best placed to identify the key priorities to address in their community. Cities are therefore encouraged to involve older people at every step of the decision-making process and develop mechanisms that will foster their participation (WHO, 2017b). A variety of mechanisms have been used in recent years to involve older people in age-friendly developments, some encouraging a more passive (e.g. information), and others a more active (e.g. co-production) form of public engagement (Rémillard-Boilard et al., 2017).

Cities that wish to undertake an age-friendly approach are finally invited to formalise their commitment to the WHO by joining the Global Network for Age-Friendly Cities and Communities. Launched by the WHO in 2010, the GNAFCC provides 'a platform for cities with shared interest in healthy ageing and age-friendly environments to network, share ideas and connect on the journey to improvement' (WHO, 2017c). Whilst it operates at the international level, the GNAFCC is supported around the world by 13 affiliated programmes. These programmes promote the approach at the local, regional, national or international level and provide a more contextualised support to cities and communities that wish to undertake an age-friendly approach. Given their proximity, the affiliated programmes are better able to offer a support that considers their local policy context and offer members the possibility to receive guidance in person, in their local language (WHO, 2017d).

The UK Network of Age-friendly Communities was recognised as the official national programme for the UK and affiliated to the GNAFCC in 2013. Whilst it encourages members to join or work towards their admission to the GNAFCC, it is worth noting that cities can be 
at different stages of their age-friendly journey when applying for membership, allowing both established and new programmes to benefit from its support. The UK Network welcomes any community from the four UK nations committed to becoming more age-friendly. In order to join the network, cities must however provide evidence (e.g. cabinet minutes, letter of commitment) that they are either already part of the GNAFCC or committed to working towards this goal.

\section{ROLE OF THE NETWORK IN SUPPORTING AGE-FRIENDLY COMMUNITIES}

Since its formation, the UK Network of Age-friendly Communities has helped drive the agefriendly agenda in the UK, promoting a more positive vision of ageing. Drawing on some of the network's key aims (Manchester Institute for Collaborative Research on Ageing [MICRA], 2017a; 2017b; UK Urban Ageing Consortium, 2014) and achievements the following section presents four ways in which this platform can support and contribute to the development of age-friendly communities.

First, by encouraging the sharing of information and maintaining close links with the research community, the network can contribute to increasing knowledge about the challenges and opportunities of urban ageing. Since the network's formation, one of the key preoccupations of member cities has been to remain up to date with current age-friendly debates and develop appropriate policy responses to age-friendly issues. Working in close collaboration with the UK Urban Ageing Consortium and the Centre for Ageing Better, the network aims to disseminate knowledge through policy seminars, events and workshops on a variety of agefriendly topics. It has also contributed to the development and sharing of various tools and resources such as the Research \& Evaluation Framework for Age-friendly Cities (Handler, 2014, p. 16), a practical document produced by the UK Urban Ageing Consortium 'to help cities and community groups, policymakers and commissioners across the UK develop successful and innovative Age-friendly programmes and initiatives'. In July 2017, Ageing Better launched an online platform to facilitate the circulation of information inside and outside the network. It is expected that 'over time, the platform will develop to include a range of resources including evidence reports, toolkits and training' (Ageing Better, 2017d), and provide guidance for communities wanting to become more age-friendly.

Second, by collecting and sharing evidence the network can help identify " what works" in terms of age-friendly practices' (MICRA, 2017b). Since its formation, the UK Network of 
Age-friendly Communities has demonstrated a strong interest to develop and test out new age-friendly approaches and practices. It is expected that the development of a partnership with the UK Centre for Ageing Better will enhance this dimension in the coming months. Ageing Better (2017e) promotes the use of lived, practice and research evidence to inform its work. The Centre has already started collecting data and mapping members' progress with the aim of gaining 'a detailed understanding of their age-friendly work' (Entwistle, 2017) and feeding back findings to participating cities. As members continue to deliver their agefriendly programmes, project evaluation is also likely to become a key feature of their work. The Centre has already started documenting good age-friendly practices and sharing examples of innovative projects on its website.

Third, by connecting cities and offering a space for knowledge exchange, the UK Network can provide an important platform for peer support and collaboration. Cities are encouraged to use the network as a platform to share their skills and discuss common challenges and solutions. Over the years, network members have had the opportunity to connect with their peers through a series of meetings, networking events and peer visits. The network received the support of the Baring Foundation to conduct a series of enquiry visits, during which network representatives were invited to act as 'critical friends' and have constructive discussions on how to better involve older people in arts and culture (UK Urban Ageing Consortium, 2013a). Members are also invited to use this platform to share innovative ideas and best practices. The development of the 'take a seat' campaign (see further below) in Manchester and Nottingham, for example, illustrates how connecting cities and encouraging knowledge sharing can contribute to the development of age-friendly initiatives. Inspired by a similar project conducted in New York, Manchester was the first city to implement the 'take a seat' campaign in the UK [2], followed by the city of Nottingham launching its campaign in 2015. The 'take a seat' initiative has since become one of the flagship projects of Nottingham's age-friendly programme and has been adopted by more than 330 local premises across the city (Nottingham City Council, 2017).

By collaborating and joining the UK Network of Age-friendly Communities, cities can finally contribute to local, national and international policies on age-friendly issues. Since the very early stages of the network, a key priority for members has been to 'create a collaborative voice to influence policy and practice' (UK Ageing Consortium, 2013b, p. 10). Cities have developed innovative partnerships and mechanisms over the years to build 
commitment and attract the support of a wide range of stakeholders (i.e. policymakers, practitioners, researchers, older people). The city of Belfast, for example, developed an allparty reference group on older people to ensure that ageing remained a priority on the city's political agenda. The reference group comprises one councillor from each of the political parties and meets four times a year to discuss ageing issues and oversee the work of agefriendly Belfast. In addition to building support at the local level, the UK Network, as a whole, has also engaged with a wide range of organisations working at the national level. The network has worked closely with the Ageing Well in Wales network, the Cymru Older People's Alliance (COPA), and the Scottish Older People's Assembly (SOPA), a charitable organisation representing and promoting the voice and experience of Scotland's older people. Through its affiliation to the GNAFCC, the network also has the opportunity to work alongside other WHO affiliated programmes, such as Age Platform Europe and the American Association of Retired Persons (AARP) Network of Age-friendly Communities, and make its voice heard within broader age-friendly debates.

\section{EXAMPLES OF SUCCESSES}

Whilst the UK Network may provide an important platform for cities to collectively advance the development of age-friendly approaches, network members have also been successful at delivering projects across a variety of age-friendly domains at the local level. The following section aims to showcase examples of projects developed across the UK and illustrate the wide range of initiatives members have undertaken as part of their respective age-friendly programmes [3].

\section{Promoting the age-friendly approach}

Network members have been determined to promote the age-friendly approach and make their city a better place to grow old. One popular way of promoting the approach has been through the development of age-friendly or older people's charters. The cities of Bristol, Leeds, Nottingham and Manchester, for example, have each developed its own charter to promote older people's rights and encourage local stakeholders to become more age-friendly. Whilst they may slightly differ in terms of content, each document sets out a series of principles to better support older residents. The Leeds' charter, for example, underlines the need for older people to 'feel valued in their community' and 'taken seriously in their concerns'. The document states that older people should be 'able to live, work and play 
where and how they want', 'have equal access to information', 'have an active role in shaping the policies which affect them' and 'never be made to feel invisible or disenfranchised from civic participation' (Leeds Older People's Forum, 2016, p. 4). Whilst the charters' principles may differ, the objective of the project is similar across all cities: residents, businesses and organisations are invited to adopt the charter and think of concrete ways they can support its principles and contribute to making the city more age-friendly.

The 'take a seat' campaign has also received increased interest amongst network members. Recognised for its simplicity, the take a seat campaign is a low-cost initiative that aims to help older people get out and about in the city (Southway Housing Trust, 2017; Nottingham City Council, 2017). The campaign invites businesses, local shops and public organisations to offer a seat to older residents so they can stop and sit down if they feel the need to rest. Local business who join this scheme are invited to apply an age-friendly logo on their window to show their commitment to the campaign and inform residents they will be offered a chair and made welcome at any time. As mentioned above, the city of Manchester and Nottingham have both been successful in delivering this scheme. The two cities have decided to extend their collaboration, using a similar age-friendly logo, so that older people travelling from one city to another can recognise more easily local businesses that have signed up to the scheme.

In addition to developing multi-sectorial projects, cities have also developed targeted initiatives on specific age-friendly issues. In Newcastle, for example, an innovative multigenerational housing project called Future Homes has emerged. Led by Newcastle University, the project brings together the academy, the local authority, the business and the voluntary sectors. The Future Homes project aims to develop sustainable housing models that create flexible living and provide support 'for everyone at any life-stage' (Newcastle City Futures, 2017). The project will be on site in June 2018 with 5 demonstrator units and, subject to negotiations, will follow on with a further 30 dwellings in the centre of Newcastle in 2019.

\section{Promoting a more positive vision of ageing}

An increased emphasis has been placed amongst network members on raising awareness and challenging negative stereotypes on ageing. The city of Coventry, for example, held a free two-day festival on older people's day to promote active ageing and longer lives. Supported by the European Commission EIT Health programme, the 'Coventry Life Festival' (2017) 
encouraged various stakeholders (i.e. citizens, health professionals, scientists, entrepreneurs) to take part in discussions around ageing and think of creative solutions to better support older residents. The city of Brighton and Hove also held a two-week festival in early October to celebrate older people's achievements and contributions to the city. Building on the success of the 2016 edition, which attracted more than 2,500 older people, the 2017 Older People's festival hosted more than 100 events for older residents across the city (Impact Initiatives, 2017a; 2017b).

Certain members have also helped raise awareness through the delivery of training programmes. The cities of Stoke-on-Trent and Manchester, for example, have developed and delivered age-friendly training sessions to local organisations and businesses. Age-Friendly Isle of Wight has also delivered training sessions to a wide range of organisations from the public, private and voluntary sectors, including the police and fire service. The partnership also worked with transport providers and developed an innovative training programme for bus drivers working on the island. In collaboration with the local bus company Southern Vectis, Age-Friendly Isle of Wight helped train all bus drivers so that they could better understand and accommodate the needs of passengers experiencing cognitive, mobility, sight or hearing problems (Age-Friendly Island, 2017).

\section{Involving older people in age-friendly developments}

In addition to challenging ageist attitudes, network members have also developed innovative ways of involving older people in age-friendly developments. The city of Manchester, for example, has developed work and research around co-production. One of the flagship projects of the Manchester Age-Friendly programme was conducted by the Manchester Institute for Collaborative Research on Ageing at the University of Manchester. Entitled 'Researching Age-Friendly Communities' the project involved the training of 18 older volunteers as co-investigators to assess the age-friendliness of three neighbourhoods (Buffel, 2015). The co-investigators conducted 68 one-to-one interviews with members of their community and helped the research reach people at higher risk of isolation and exclusion. The study was highlighted in the WHO World Report on Ageing and Health (2015, p. 222) and described as 'a significant methodological step forward in developing new models for community engagement'. 
Whilst more established programmes might be further along their age-friendly journey, it is finally important to mention that more recent programmes have also shown a strong interest in consulting and capturing the needs of their older population. Having recently started their age-friendly journey, the London Borough of Lewisham is currently building its application to join the GNAFCC and evaluating its level of age-friendliness. The borough consulted its population through various means during the past few months, notably by conducting focus groups and administering postal and online surveys (Lewisham Council, 2017). This consultation will help the borough gather baseline data and help ensure that its age-friendly programme is developed in a 'cycle of continual improvement' (WHO, 2017b).

\section{CONCLUSION}

This article aimed to document the experience of the UK Network of Age-friendly Communities in supporting the development of age-friendly communities across the UK. As this article illustrates, despite its limited resources the UK Network has provided cities with an important platform for knowledge exchange and peer support over the years, and helped build commitment to the age-friendly agenda at the local, national and international level. Whilst the lack of resources may have limited the scope of its work thus far, the establishment of a partnership with the Centre for Ageing Better opens interesting avenues for the future of the network. The role of this platform is prone to expand in a near future as Ageing Better (2016, p. 2) committed to supporting members with 'access[ing], develop[ing], shar[ing] and apply[ing] learning and evidence of what works in practice' in terms of agefriendly developments. Over the coming months, the two partners would notably like to foster the exchange of information inside and outside the network and produce new tools, training and resources to support local communities. With the support of Ageing Better, network members would also like to raise the profile of their respective age-friendly work and 'build commitment to this agenda across the public and voluntary sectors, businesses and residents' (Ageing Better, 2016, p. 2). Collectively, members also aim to strengthen their collaborative national voice and reflect on ways to ensure the network's sustainability. Despite its existing achievements and future ambitions, the question remains as to how this platform, and age-friendly initiatives in general, may be sustained in a context of scarce resources. By collecting and sharing evidence, monitoring the evolution of their programmes and disseminating examples of good practices, network members are not only likely to strengthen their own work, but can also help demonstrate the benefits of the age-friendly 
approach. As the age-friendly movement develops, gathering knowledge on age-friendly initiatives and programmes will be key to building support for this approach and an important priority to address to ensure its sustainability.

\section{NOTES}

1. The University of Manchester also joined the UK Urban Ageing Consortium in 2012.

2. The project was initially set in motion by Southway Housing Trust, a charitable housing association from Manchester.

3. For further information about these initiatives or participating cities see: https://www.ageing-better.org.uk/our-work/area/age-friendly-communities/age-friendlycommunities-members/

\section{ACKNOWLEDGEMENTS}

The author would like to thank Jessica Entwistle for her support and assistance in the development of this paper, Professor Chris Phillipson and Paul McGarry for their valuable feedback, network representatives who provided additional information on their respective programmes, and the Manchester Institute for Collaborative Research on Ageing. This work has been supported by the Social Sciences and Humanities Research Council of Canada (SSHRC) through a Doctoral Fellowship, the University of Manchester School of Social Sciences, and Manchester City Council.

\section{REFERENCES}

Age-Friendly Island (2017), "Age Friendly Bus Driver", available at: http://agefriendlyisland.org/age-friendly-communities-work-with-southern-vectis-busdrivers/ (accessed 30 November 2017).

Beth Johnson Foundation (2017), "Beth Johnson Foundation", available at: https://www.bjf.org.uk/ (accessed 19 November 2017).

Buffel, T. (2015), Researching Age-Friendly Communities. Stories from Older People as CoInvestigators. The University of Manchester Library, Manchester.

Buffel, T., Handler, S. and Phillipson, P. (Eds.) (2018), Age-friendly cities and communities. A global perspective. Policy Press, Bristol.

Cabinet Office (2017), "What Works Network", available at: https://www.gov.uk/guidance/what-works-network (accessed 14 November 2017). 
Center for Ageing Better (2016), "Job Description", available at:

http:/www.greatersport.co.uk/media/uploads/a5b52ce3-7f39-48f8-923c-

2c6485e27834.pdf (accessed 29 November 2017).

Centre for Ageing Better (2017a), "Our work", available at https://www.ageingbetter.org.uk/our-work/(accessed 17 October 2017).

Centre for Ageing Better (2017b), "Why we're here", available at https://www.ageingbetter.org.uk/about-ageing-better/why-were-here/ (accessed 17 October 2017).

Centre for Ageing Better (2017c), "UK Network of Age-friendly Communities", available at https://www.ageing-better.org.uk/our-work/area/age-friendly-communities/ (accessed 17 October 2017).

Centre for Ageing Better (2017d), "New web resource will help communities to 'age better'", available at https://www.ageing-better.org.uk/news/new-web-resource-will-helpcommunities-age-better/ (accessed 17 October 2017).

Centre for Ageing Better (2017e), "Our approach to evidence", available at https://www.ageing-better.org.uk/about-ageing-better/what-we-do/evidence/ (accessed 17 October 2017).

Coventry Life Festival (2017), "Coventry Life Festival", available at https://www.coventrylifefestival.co.uk/ (accessed 28 November 2017).

Entwistle, J. (2017), "UK Network of Age-Friendly Communities. Centre for Ageing Better", Unpublished PowerPoint presentation presented at the Initial Steering Meeting of the UK Network of Age-friendly Communities, 21 April 2017.

Handler, S. (2014), A Research \& Evaluation Framework for Age-friendly Cities, UK Urban Ageing Consortium, Manchester.

House of Lords (2013), Ready for Ageing? Select Committee on Public Service and Demographic Change. Report of Session 2012-13. HL Paper 140. The Stationery Office, London.

Impact Initiative (2017a), "Join in the fun at the Older People's Festival 2017", available at https://www.homewise.co.uk/blog/join-fun-opf-2017/ (accessed 28 November 2017).

Impact Initiative (2017b), "Older People's Festival", [Facebook] $25^{\text {th }}$ September, available at https://www.facebook.com/olderpeoplesfestival/ (accessed 28 November 2017).

Leeds Older People's Forum (2016), "An Age-Friendly Charter for Leeds", available at: https://s3-eu-west-1.amazonaws.com/assets.timetoshine.co.uk/Charter-Report-DigitalCompressed.pdf (accessed 17 October 2017).

Lewisham Council (2017), "Survey on the age-friendliness of Lewisham", available at: https://lewisham-consult.objective.co.uk/portal/community_services/cnd/agefriendly lewisham (accessed 30 November 2017). 
Manchester Institute for Collaborative Research on Ageing (2017a), "Aims of the UK Network", available at: http://www.micra.manchester.ac.uk/research/projects-andgroups/age-friendly-cities/aims/ (accessed 17 October 2017).

Manchester Institute for Collaborative Research on Ageing (2017b), "UK Network of Agefriendly Cities. Learning and collaboration", available at: http://www.micra.manchester.ac.uk/research/projects-and-groups/age-friendlycities/learning-and-collaboration/ (accessed 17 October 2017).

McGarry, P. and Morris, J. (2011), "A great place to grow older: a case study of how Manchester is developing an age-friendly city", Working with Older People, Vol. 15 No. 1, pp. 38-46.

Moulaert, T. and Garon, S. (Eds) (2016), Age-Friendly Cities and Communities in International Comparison. Political Lessons, Scientific Avenues, and Democratic Issues, Springer International Publishing, Cham.

Newcastle City Futures (2017), "Future Homes: Future Housing for an Ageing Society", available at: http://www.newcastlecityfutures.org/projects/future-homes/ (accessed 29 November 2017).

Nottingham City Council (2017), "Take a Seat", available at https://www.nottinghamcity.gov.uk/health-and-social-care/adult-social-care/take-a-seat/ (accessed 29 November 2017).

Rémillard-Boilard, S., Buffel, T. and Phillipson, C. (2017), "Involving older residents in agefriendly developments: from information to coproduction mechanisms", Journal of Housing For the Elderly, Vol. 31, No. 2, pp. 146-59.

Southway Housing Trust (2017), "Age-Friendly document templates", available at: http://www.southwayhousing.co.uk/your-neighbourhood/age-friendlyneighbourhoods/age-friendly-take-a-seat-document-templates (accessed 29 November 2017).

UK Urban Ageing Consortium (2013a), "Age-friendly Cities Network. Enquiry visit to Newcastle upon Tyne. 19 June 2013. Arts and older people. Insight report", available at: http://www.qualityoflife.org.uk/source/Enquiry-visit-final-report.pdf (accessed 17 October 2017).

UK Urban Ageing Consortium (2013b), "UK Network of Age-friendly Cities. Art and older people enquiry visit programme - summary report", available at: https://www.bjf.org.uk/web/documents/page/Arts\%20\%20Older\%20People.pdf (accessed 17 October 2017).

UK Urban Ageing Consortium (2014), "Invitation to tender. Coordination of the UK Network of Age-friendly Cities", available at: https://www.manchestercommunitycentral.org/sites/manchestercommunitycentral.co.uk /files/Invitation\%20to\%20tender.pdf (accessed 17 October 2017).

Warth, L. (2016), "The WHO Global Network of Age-Friendly Cities and Communities: origins, developments and challenges", in Moulaert, T. and Garon, S. (Eds), AgeFriendly Cities and Communities in International Comparison. Political Lessons, 
Scientific Avenues, and Democratic Issues, Springer International Publishing, Cham, pp. 37-46.

World Health Organization (2007), Global Age-friendly Cities: A Guide, WHO, Geneva.

World Health Organization (2015), World Report on Ageing and Health, WHO, Geneva.

World Health Organization (2017a), "Welcome to Age-friendly World", available at: https://extranet.who.int/agefriendlyworld/ (accessed 19 November 2017).

World Health Organization (2017b), "Ageing and life-course. Network cycle of continual improvement", available at: http://www.who.int/ageing/age_friendly_cities_process/en/ (accessed 17 October 2017).

World Health Organization (2017c), "Frequently asked questions regarding the WHO Global Network for Age-friendly Cities and Communities (GNAFCC) and Age-Friendly World", available at: http://www.who.int/ageing/gnafcc-faq.pdf?ua=1 (accessed 17 October 2017).

World Health Organization (2017d), "Age-Friendly World. Adding life to years. Affiliated Programmes", available at: https://extranet.who.int/agefriendlyworld/affiliatedprogrammes/ (accessed 19 November 2017). 